\title{
Polynomial cointegration tests of anthropogenic impact on global warming
}

\author{
M. Beenstock ${ }^{1}$, Y. Reingewertz ${ }^{2}$, and N. Paldor ${ }^{3}$ \\ ${ }^{1}$ Department of Economics, the Hebrew University of Jerusalem, Mount Scopus Campus, Jerusalem, Israel \\ ${ }^{2}$ Department of Economics, the George Washington University, 2115 G St, Washington DC, USA \\ ${ }^{3}$ Fredy and Nadine Herrmann Institute of Earth Sciences, the Hebrew University of Jerusalem, Edmond J. Safra Campus, \\ Givat Ram, Jerusalem, Israel \\ Correspondence to: N. Paldor (nathan.paldor@ huji.ac.il)
}

Received: 6 May 2012 - Published in Earth Syst. Dynam. Discuss.: 16 July 2012

Revised: 24 October 2012 - Accepted: 30 October 2012 - Published: 21 November 2012

\begin{abstract}
We use statistical methods for nonstationary time series to test the anthropogenic interpretation of global warming (AGW), according to which an increase in atmospheric greenhouse gas concentrations raised global temperature in the 20th century. Specifically, the methodology of polynomial cointegration is used to test AGW since during the observation period (1880-2007) global temperature and solar irradiance are stationary in 1st differences, whereas greenhouse gas and aerosol forcings are stationary in 2nd differences. We show that although these anthropogenic forcings share a common stochastic trend, this trend is empirically independent of the stochastic trend in temperature and solar irradiance. Therefore, greenhouse gas forcing, aerosols, solar irradiance and global temperature are not polynomially cointegrated, and the perceived relationship between these variables is a spurious regression phenomenon. On the other hand, we find that greenhouse gas forcings might have had a temporary effect on global temperature.
\end{abstract}

\section{Introduction}

Considering the complexity and variety of the processes that affect Earth's climate, it is not surprising that a completely satisfactory and accepted account of all the changes that occurred in the last century (e.g. temperature changes in the vast area of the Tropics, the balance of $\mathrm{CO}_{2}$ input into the atmosphere, changes in aerosol concentration and size and changes in solar radiation) has yet to be reached (IPCC, AR4, 2007). Of particular interest to the present study are those processes involved in the greenhouse effect, whereby some of the longwave radiation emitted by Earth is re-absorbed by some of the molecules that make up the atmosphere, such as (in decreasing order of importance): water vapor, carbon dioxide, methane and nitrous oxide (IPCC, 2007). Even though the most important greenhouse gas is water vapor, the dynamics of its flux in and out of the atmosphere by evaporation, condensation and subsequent precipitation are not understood well enough to be explicitly and exactly quantified.

While much of the scientific research into the causes of global warming has been carried out using calibrated general circulation models (GCMs), since 1997 a new branch of scientific inquiry has developed in which observations of climate change are tested statistically by the method of cointegration (Kaufmann and Stern, 1997, 2002; Stern and Kaufmann, 1999, 2000; Kaufmann et al., 2006a,b; Liu and Rodriguez, 2005; Mills, 2009). The method of cointegration, developed in the closing decades of the 20th century, is intended to test for the spurious regression phenomena in nonstationary time series (Phillips, 1986; Engle and Granger, 1987). Non-stationarity arises when the sample moments of a time series (mean, variance, covariance) depend on time. Regression relationships are spurious ${ }^{1}$ when unrelated nonstationary time series appear to be significantly correlated because they happen to have time trends.

The method of cointegration has been successful in detecting spurious relationships in economic time series data ${ }^{2}$.

\footnotetext{
1 "Spurious regression" was originally discovered by Yule (1897).

${ }^{2}$ For example, Enders (1988) in the case of Purchasing Power Parity theory, Johansen and Juselius (1998) in the case
} 
Indeed, cointegration has become the standard econometric tool for testing hypotheses with nonstationary data (Maddala, 2001; Greene, 2012). As noted, climatologists too have used cointegration to analyse nonstationary climate data (Kaufmann and Stern, 1997). Cointegration theory is based on the simple notion that time series might be highly correlated even though there is no causal relation between them. For the relation to be genuine, the residuals from a regression between these time series must be stationary, in which case the time series are "cointegrated". Since stationary residuals meanrevert to zero, there must be a genuine long-term relationship between the series, which move together over time because they share a common trend. If on the other hand, the residuals are nonstationary, the residuals do not mean-revert to zero, the time series do not share a common trend, and the relationship between them is spurious because the time series are not cointegrated. Indeed, the $R^{2}$ from a regression between nonstationary time series may be as high as 0.99 , yet the relation may nonetheless be spurious.

The method of cointegration originally developed by Engle and Granger (1987) assumes that the nonstationary data are stationary in changes, or first-differences. For example, temperature might be increasing over time, and is therefore nonstationary, but the change in temperature is stationary. In the 1990 s cointegration theory was extended to the case in which some of the variables have to be differenced twice (i.e. the time series of the change in the change) before they become stationary. This extension is commonly known as polynomial cointegration. Previous analyses of the non-stationarity of climatic time series (e.g. Kaufmann and Stern, 2002; Kaufmann et al., 2006a; Stern and Kaufmann, 1999) have demonstrated that global temperature and solar irradiance are stationary in first differences, whereas greenhouse gases (GHG, hereafter) are stationary in second differences. In the present study we apply the method of polynomial cointegration to test the hypothesis that global warming since 1850 was caused by various anthropogenic phenomena. Our results show that GHG forcings and other anthropogenic phenomena do not polynomially cointegrate with global temperature and solar irradiance. Therefore, despite the high correlation between anthropogenic forcings, solar irradiance and global temperature, AGW is not statistically significant. The perceived statistical relation between temperature and anthropogenic forcings is therefore a spurious regression phenomenon.

\section{Data and methods}

We use annual data (1850-2007) on greenhouse gas $\left(\mathrm{CO}_{2}\right.$, $\mathrm{CH}_{4}$ and $\mathrm{N}_{2} \mathrm{O}$ ) concentrations and forcings, as well as on forcings for aerosols (black carbon, reflective tropospheric aerosols). We also use annual data (1880-2007) on solar

of the influential Keynesian IS-LM model, and Hendry and Ericsson (1991) on the demand for money. irradiance, water vapor (1880-2003) and global mean temperature (sea and land combined 1880-2007). These widely used secondary data are obtained from NASA-GISS (Hansen et al., 1999, 2001). Details of these data may be found in the Data Appendix.

We carry out robustness checks using new reconstructions for solar irradiance from Lean and Rind (2009), for globally averaged temperature from Mann et al. (2008) and for global land surface temperature (1850-2007) from the Berkeley Earth Surface Temperature Study.

Key time series are shown in Fig. 1 where panels $a$ and $b$ show the radiative forcings for three major GHGs, while panel c shows solar irradiance and global temperature. All these variables display positive time trends. However, the time trends in panels $\mathrm{a}$ and $\mathrm{b}$ appear more nonlinear than their counterparts in panel c. Indeed, statistical tests reported below reveal that the trends in panel $\mathrm{c}$ are linear, whereas the trends in panels $\mathrm{a}$ and $\mathrm{b}$ are quadratic. The trend in solar irradiance weakened since 1970, while the trend in temperature weakened temporarily in the 1950s and 1960s.

The statistical analysis of nonstationary time series, such as those in Fig. 1, has two natural stages. The first consists of unit root tests in which the data are classified by their order and type of non-stationarity. If the data are nonstationary, sample moments such as means, variances and covariances depend upon when the data are sampled, in which event least squares and maximum likelihood estimates of parameters may be spurious. In the second stage, these nonstationary data are used to test hypotheses using the method of cointegration, which is designed to distinguish between genuine and spurious relationships between time series. Since these methods may be unfamiliar to readers of Earth System Dynamics, we provide an overview of key concepts and tests.

\subsection{Unit root tests}

A time series is (weakly) stationary if its sample moments (means, variances and covariances) do not depend on when they are measured. By definition, a time series is nonstationary or integrated to order $d, I(d)$ for short, if its $d$-th difference is stationary but its $d-1$-th difference is not. We quantify the order of the data's non-stationarity using a variety of unit root tests. The most well-known is the Dickey-Fuller (DF) test statistic (Dickey and Fuller, 1981), which is based on the null hypothesis that the variable is nonstationary, and $d=1$. The KPSS test statistic (Kwiatkowski et al., 1992) is based on the null hypothesis that $d=0$, in which case the variable is stationary. The DF and KPSS tests assume that $d$ is an integer equal to 1 and 0 , respectively. In fact a variable is nonstationary if $d \geq 1 / 2$ (Granger and Joyeaux, 1980). Rejection of the KPSS null means therefore that $d$ does not equal zero, but the variable could still be stationary. Rejection of the DF null means that $d<1$, but it would still be nonstationary if $1 / 2 \leq d<1$. Therefore, the two tests are not mirror images of each other. In any case, failure to reject a hypothesis is 
not logically equivalent to establishing that its antithesis is false $^{3}$. Given the low power of these tests there is a case for using both types of test (Maddala and Kim, 1998). Geweke and Porter-Hudak (1983) suggested an estimator for $\mathrm{d}$ as a fraction, which we use below. For an application to climate data see Mills (2007).

If $d=1$ the variable is "difference stationary". If deviations of the variable from a deterministic linear trend are stationary, the variable is "trend stationary". In the latter case random shocks to the variable are expected to dissipate over time as the trend is re-established, and the time trend is therefore deterministic. In the former case, random shocks are expected to persist over time and the trend is therefore stochastic. Critical values for the DF and KPSS statistics are more stringent in the former case because the trend stationary model involves the estimation of an additional parameter (time trend). In the event that both models appear to be consistent with the data, Dickey and Fuller (1981) have proposed a test that distinguishes between trend stationarity and difference stationarity. If a variable is trend stationary, it obviously cannot be stationary.

The DF and KPSS statistics assume that the residuals in the data generating process are serially independent. If they are not, these statistics have to be corrected. The augmented DF statistic (ADF, see Said and Dickey, 1984) assumes that the serial correlation is induced by dynamics in the data generating process (DGP). Another correction for the DF statistic is the DF-GLS statistic (i.e. DF statistic estimated by Generalised Least Squares see Elliott et al., 1996), which assumes that serial correlation in the DGP is inherent and is estimated by generalised least squares (GLS). The PhillipsPerron (PP) statistic (Phillips and Perron, 1988) is a robust estimate of the DF statistic, which corrects its standard deviation for serial correlation in the DGP. A similar correction method is also used by KPSS. Unfortunately, there is no consensus on the best way to handle this serial correlation problem although the PP statistic is reckoned to be inferior (Maddala and Kim, 1998; Davidson and MacKinnon, 2009, chapter 14). Our own preference is to augment the ADF test until its residuals are serially independent according to a lagrangemultiplier test statistic.

Stationary time series which contain structural breaks may appear nonstationary because their mean varies over time. The same applies to trend stationary time series which contain structural breaks. For example, Kaufmann et al. (2010) show that global temperature is not trend stationary in the presence of structural breaks, and that it is difference stationary. See Perron and Vogelsang (1992) regarding DF tests in the presence of structural breaks and Lee and Strazicich (2001) for KPSS tests in the presence of structural breaks.

\footnotetext{
${ }^{3}$ Just as failure to establish guilt is not equivalent to establishing innocence.
}

\subsection{Cointegration tests}

Cointegration tests typically refer to hypothesized steadystate relationships in the data. This feature is particularly useful because it means that it is unnecessary to specify auxiliary hypotheses regarding dynamic convergence processes towards steady states. Although this methodological simplification applies asymptotically, it has a number of important advantages. First, steady states may be inherently more interesting than adjustment paths. In the case of AGW the main interest is the long-term anthropogenic impact on climate rather than how it diffuses over time. Secondly, tests of the steady state are robust asymptotically with respect to unknown paths of adjustment. Often, steady state theory is more developed than its ancillary theory of adjustment. These adjustment theories may be nonlinear, as they commonly are in GCMs, but cointegration does not require the specification of these details. Third, estimates of long-term cointegrated relationship are "super-consistent"; the relationship between temperature and forcing is asymptotically identified even if there happens to be reverse causality from temperature to forcing.

If the steady state is linear (i.e. the assumed relationship between the variables in the regression model is linear) then linear cointegration theory is sufficient to test restrictions regarding the steady state. If the steady state is nonlinear then nonlinear cointegration theory may be used to test relevant restrictions about the steady state (Choi and Saikkonen, 2010). Nonlinear cointegration theory is naturally more complex than its linear counterpart. GCMs are nonlinear because they embody nonlinear terms and adjustment processes rather than nonlinear steady states. Therefore, for the most part we focus on linear cointegration tests. However, we also use nonlinear cointegration theory to test AGW in nonlinear contexts.

Several different cointegration methodologies are available. The original methodology proposed by Engle and Granger (1987), based on ordinary least squares (OLS), is designed for "asymptotic samples" in which the steady state is repeatedly observable. Typically, this requires long time series in terms of calendar time. In our case we use annual data from 1850 or 1880 . If the adjustment process of temperature with respect to forcings is very protracted this sample may be too short to test hypotheses about steady states. Engle and Yoo (1991) have suggested a test to determine whether estimates based on the Engle-Granger methodology are subject to finite sample bias. We use this test to show that the sample is sufficiently long.

Other cointegration methodologies have been proposed for non-asymptotic samples in which the steady state may be concealed by short-term adjustment processes in the data. These include the methodology of Johansen (1988), the dynamic ordinary least squares (DOLS) methodology of Stock and Watson (1993) and the error correction (ECM) methodology (Ericsson and MacKinnon, 2002). All these 
methodologies filter out (in different ways) short-term dynamics in the data that may conceal the hypothesized steady states. In all of these methodologies the null hypothesis is "no cointegration, or spurious regression relationships". Shin (1994) has extended the KPSS methodology (see above) to test the null hypothesis $d=0$ for the model residuals, in which case the model is cointegrated.

\subsection{Polynomial cointegration}

In standard cointegration tests the variables must be difference stationary in which case all the variables are $I(0)$. Just as $I(0)$ and $I(1)$ variables cannot be cointegrated, so $I(1)$ and $I(2)$ variables do not cointegrate. An exception arises in the case of polynomial cointegration. Therefore, if some of the variables happen to be $I(2)$ the null hypothesis of AGW may be tested using polynomial cointegration. In the present context this happens when the $I(2)$ variables, which are anthropogenic, are cointegrated $I(1)$. We refer below to this $I$ (1) variable as the "anthropogenic anomaly". If the latter is cointegrated with temperature and solar irradiance, which are both $I(1)$ variables, the variables are polynomially cointegrated, and AGW would be corroborated.

There are also different methodologies for polynomial cointegration, which have been reviewed by Maddala and Kim (1998). Haldrup (1994) extended the EngleGranger methodology to polynomial cointegration, as did Johansen (1995) for his methodology, and Stock and Watson (1993) for their methodology. There are conceptual differences between these methodologies. Haldrup's methodology hypothesizes that the $I(2)$ variables may "cointegrate down" to an $I(1)$ variable, i.e. they share a common stochastic trend. Johansen's methodology hypotheses the existence of a deterministic trend among the $I(2)$ variables $^{4}$. In the context of greenhouse gas forcing this means that there is an autonomous time trend causing forcing to diverge over time.

We prefer Haldrup's methodology over Johansen's for several reasons. First, there is no physical justification for an autonomous time trends in greenhouse gas forcing. For example, the anthropogenic component of $\mathrm{CO}_{2}$ forcing depends on world consumption of hydrocarbons, which has a stochastic trend rather than a deterministic trend. Therefore, $\mathrm{CO}_{2}$ forcing should not have a deterministic trend (as confirmed by our unit root tests). Second, Johansen's method is less robust than least squares methods (Maddala and Kim, 1998, p. 173) due to its greater parametricity ${ }^{5}$. On the other hand,

\footnotetext{
${ }^{4}$ In reference to Johansen's $I$ (2) estimator Juselius (2007) notes (p. 315) that, "In particular, this means that we need to allow for trend-stationary relations as a starting hypothesis."

${ }^{5}$ Juselius (2007) writes (p. 55) in relation to the assumption that the residuals in Johansen's method must be multivariate normal, "If they do not pass these tests, for example, because they are autocorrelated or heteroscedastic, or because the distribution is skewed or leptokurtic, then the estimates may no longer have optimal properties and cannot be considered full-information maximum likelihood
}

Johansen's method takes account of feedback between the covariates. However, this advantage does not apply in our case since for physical reasons there is no feedback between solar irradiance and greenhouse gas forcing, nor does temperature feedback onto solar irradiance and greenhouse gas forcing. Fourth, as noted by Davidson and MacKinnon (2009, p. 617), Johansen's methodology is more prone to finite sample bias than its least squares alternatives. Therefore, if we suspect that our sample is insufficiently long, it is preferable to use least squares methods. Fifth, as noted by Maddala and Kim (1998, p. 203), the Engle-Granger procedure upon which Haldrup's method is based is statistically underpowered, i.e. it tends to accept false negative results by more than it should. In the present context this means that our polynomial cointegration methodology is too "soft" with respect to AGW. Since a positive result might have been incorrect, rejection of AGW is in some sense against the odds, and therefore more convincing. A final reason is that previous researchers have used least squares methods. Therefore, Haldrup's method enables us to reconstruct incorrect inferences in previous least squares studies which ignored the important fact that greenhouse gas forcing is $I(2)$.

Parameters estimated from stationary time series are root$\mathrm{T}$ consistent, where $T$ denotes the number of observations. If the data are $I(1)$, have stochastic trends and are cointegrated, the parameter estimates are $T^{3 / 2}$-consistent, or

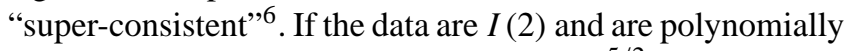
cointegrated the parameter estimates are $T^{5 / 2}$-consistent, or "super-super consistent" tency, the faster the parameter estimates converge in probability to their true values. The super-super consistency property of polynomial cointegration means, in theory, that one learns from $150 \mathrm{yr}$ of climate data what would have required at least a millennium of stationary data.

We do not report $t$-statistics for the parameter estimates in the cointegrating vector because it is well-known that when the data are nonstationary the parameter estimates based on OLS typically have non-standard distributions. This is particularly the case when variables such as temperature and greenhouse gas forcing may be dynamically dependent. Since $t$ tests and chi-squared tests are invalid, we test rival hypotheses by carrying out nested cointegration tests. For example, suppose that temperature, solar irradiance and greenhouse

(FIML) estimates. The obtained parameter estimates may not have any meaning, and since we do not know their "true" properties, inference is likely to be hazardous." We might add that the Johansen method is based on concentrated ML, which assumes that short-run dynamics in the data may be concentrated out independently of their long-run behavior. In short, the robustness of Johansen's method is weakened by its numerous assumptions.

${ }^{6}$ If, instead, the data are $I(1)$ because they are driftless random walks then the parameter estimates are root $-T$ consistent. See Maddala and Kim (1998), p. 59.

${ }^{7}$ In the absence of drift the parameter estimates would be $T^{2}$ consistent as in Haldrup (1994). 
gas forcings seem to be cointegrated. To test whether cointegration arises because of the specification of greenhouse gas forcings, we omit these forcings from the model (jointly or severally) and test whether temperature and solar irradiance are still cointegrated. If they are not cointegrated, we confirm that greenhouse gas forcings should be specified and AGW is confirmed. In the opposite case the model is cointegrated without greenhouse forcings, AGW is rejected and temperature in the steady state depends entirely on solar irradiance.

\subsection{Stochastic energy balance models (SEBM)}

We use the stochastic energy balance model (SEBM) to motivate our cointegration tests. SEBM (North et al., 1981) is written as

$C \frac{\Delta T_{t}}{\Delta t}=-\lambda T_{t-1}+F_{t}+e_{t}$

where $T$ here denotes temperature, $F$ denotes forcing, $e$ denotes a stochastic iid (identically and independently distributed) component, subscript $t$ denotes discrete time at the end of the period, and $\lambda / C$ is the rate at which temperature converges to its steady state. Normalizing $\Delta t$ to unity, the general solution to Eq. (1) for $T$ is

$T_{t}=\frac{1}{C} \sum_{i=0}^{t} \rho^{i}\left(F_{t-i}+e_{t-i}\right)+\kappa \rho^{t}$

where $0<\rho=1-\lambda / C<1$ and $\kappa$ is an arbitrary constant reflecting initial conditions. Since $\rho<1$ the final term in Eq. (2) tends zero. Suppose forcing is a random walk with drift:

$\Delta F_{t}=\phi+f_{t}$

where $f$ is a random variable which is identically and independently distributed (iid). Substituting Eq. (3) into Eq. (2) for $F_{t-i}$ gives

$T_{t}=\alpha+\beta F_{t}+u_{t}$

$\alpha=-\frac{\rho \phi}{C(1-\rho)^{2}} ; \beta=\frac{1}{C(1-\rho)}$

$u_{t}=\frac{1}{C} \sum_{i=0}^{t} \rho^{i} e_{t-i}-\frac{1}{\lambda} \sum_{i=0}^{t} \rho^{i+1} f_{t-i}$.

Equation (4) decomposes temperature into a stationary, serially correlated component $(u)$ and a nonstationary component, $F$. Finally, we disaggregate forcing $(F)$ into its component parts:

$T_{t}=\alpha+\beta_{s} S_{t}+\beta_{g} G_{t}-\beta_{a} A_{t}+u_{t}$,

where $S$ denotes solar irradiance, $G$ denotes greenhouse gas forcing, $A$ denotes aerosols and the $\beta$ coefficients are parameters to be estimated. SEBM predicts that the steady-state parameters in Eq. (5) are positive. The model is cointegrated if the residual error, $\mathrm{u}$, is stationary $I(0)$. If the residuals are nonstationary the estimated model is spurious. Equation (5) is assumed to be linear, but it may also be specified to be nonlinear.

\subsection{Dependent and independent forcings}

We distinguish between dependent or endogenous forcing and independent or exogenous forcing, denoted by $F_{\mathrm{A}}$ and $F_{\mathrm{B}}$, respectively, where $F=F_{\mathrm{A}}+F_{\mathrm{B}}$. Dependent forcing depends on global temperature and perhaps other forcing, while independent forcing is also driven by factors other than those considered here. For example, greenhouse gas and aerosol forcings are independent because they do not depend on temperature. Solar irradiance is obviously independent because what happens to the sun is independent of what happens on earth. Water vapor forcing on the other hand is dependent because it depends on temperature.

Suppose that dependent forcings are linearly related in the long run to their independent counterparts and global temperature as follows:

$F_{\mathrm{B} t}=\pi F_{\mathrm{A} t}+\mu T_{t}+\omega_{t}$

where $\pi$ denotes the effect of independent forcing on dependent forcing, $\mu$ denotes the effect of temperature on dependent forcing and $\omega$ denotes a stationary error. Equation (6) states that dependent forcings are cointegrated with independent forcings and temperature. Substituting Eq. (6) into Eq. (4) gives

$T_{t}=\psi_{0}+\psi_{1} F_{\mathrm{A} t}+v_{t}$

where:

$\Psi_{0}=\frac{\alpha}{1-\beta \mu}, \quad \Psi_{1}=\beta \frac{1+\pi}{1 \beta \mu}, \quad v_{t}=\frac{\beta \omega_{t}+u_{t}}{1-\beta \mu}$.

Equation (7) states that temperature varies directly with independent forcing. However, the coefficient $\psi_{1}$ reflects the direct effect of forcing $(\beta)$ and the indirect effect of $F_{\mathrm{A}}$ and temperature through $F_{\mathrm{B}}$. Typically, $\psi_{1}>\beta$ because $\pi>0$ and $\beta \mu<1$, i.e. the total long-run effect of independent forcing is greater than its direct effect. Since $\omega$ and $u$ are stationary so must $v$ be stationary.

What is important for our purposes is that cointegration tests do not require data on dependent forcing since $\psi_{1}=0$ when $\beta=0$. Therefore, dependent variables, such as water vapor and ocean heat, do not in principle affect cointegration tests. This conclusion is consistent with Stern (2006) who shows that cointegration tests of the relationship between temperature and forcing do not depend on the relationship between temperature and ocean heat. If Eq. (6) is cointegrated, so must Eq. (4) be cointegrated. If, however, Eq. (6) is not cointegrated because $\pi=\mu=0$ (ocean heat and water vapor do not depend in the long-run on temperature and solar irradiance) Eq. (4) may still be cointegrated, because $\psi_{1}=\beta$ in Eq. (7). 

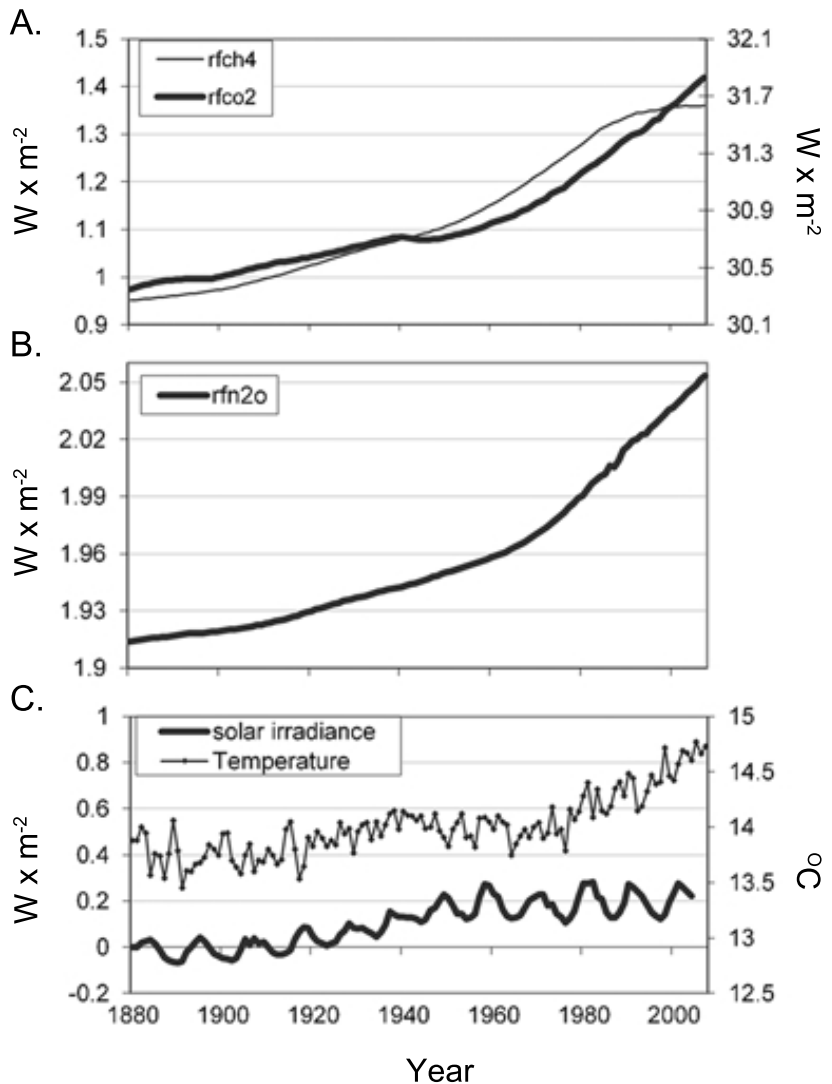

Fig. 1. Time series of the changes that occurred in several variables that affect or represent climate changes during the 20th century. (a) Radiative forcings (rf, in units of $\mathrm{W} \mathrm{m}^{-2}$ ) during 1880 to 2007 of $\mathrm{CH}_{4}$ (methane) and $\mathrm{CO}_{2}$ (carbon dioxide); (b) same period as in panel a but for Nitrous-Oxide $\left(\mathrm{N}_{2} \mathrm{O}\right)$; (c) solar irradiance (left ordinate, units of $\mathrm{W} \mathrm{m}^{-2}$ ) and annual global temperature (right ordinate, units of ${ }^{\circ} \mathrm{C}$ ) during 1880-2003.

Although they are not of direct importance here, the parameters of Eq. (6) may be estimated if data are available on dependent forcings. However, the estimates of $\pi$ and $\mu$ may not be uniquely identified since according to Eq. (4) there is reverse causality from dependent forcing to temperature. Since consistent estimate of $\beta$ require consistent estimates of $\pi$ and $\mu$ as well as consistent estimates of $\psi_{1}, \beta$ is not identified. What is required for identification is a variable that directly affects dependent forcings $\left(F_{\mathrm{B}}\right)$, but which does not directly affect temperature. Nevertheless, below we report some empirical estimates of Eq. (6).

Finally, $F_{\mathrm{A}}$ may be decomposed into $I(1)$ and $I(2)$ components. $F_{\mathrm{A}}$ must be $I(2)$ if at least one of its components is $I(2)$. In the next section we show that although solar irradiance is $I(1)$, anthropogenic forcings are $I(2)$.

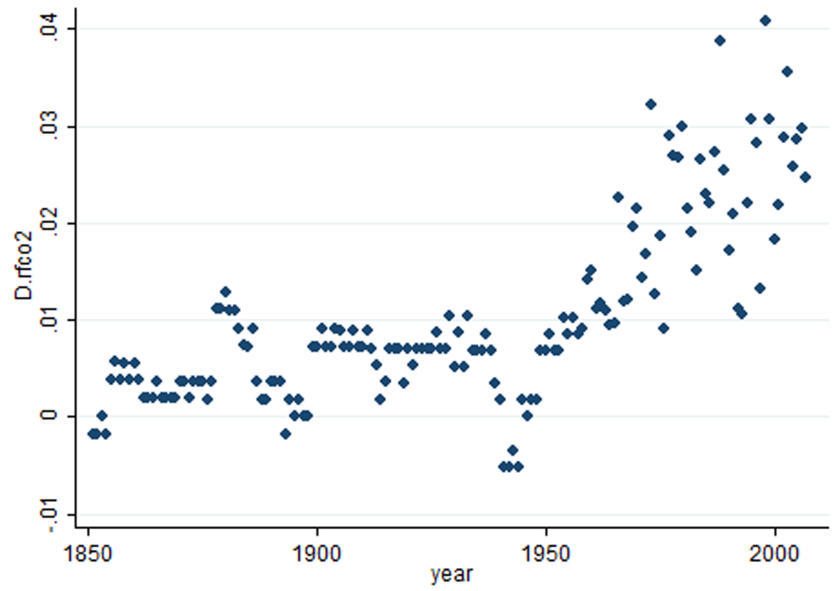

Fig. 2. Time series of the first differences of $\mathrm{rCO}_{2}$.

\section{Results}

\subsection{Time series properties of the data}

Informal inspection of Fig. 1 suggests that the time series properties of greenhouse gas forcings (panels a and b) are visibly different to those for temperature and solar irradiance (panel c). In panels a and b there is evidence of acceleration, whereas in panel $\mathrm{c}$ the two time series appear more stable. In Fig. 2 we plot $\mathrm{rfCO}_{2}$ in first differences, which confirms by eye that $\mathrm{rfCO}_{2}$ is not $I(1)$, particularly since 1940 . Similar figures are available for other greenhouse gas forcings. In this section we establish the important result that whereas the first differences of temperature and solar irradiance are trend free, the first differences of the greenhouse gas forcings are not. This is consistent with our central claim that anthropogenic forcings are $I(2)$, whereas temperature and solar irradiance are $I(1)$.

What we see informally is born out by the formal statistical tests for the variables in Table 1. Although the KPSS and DF-type statistics (ADF, PP and DF-GLS) test different null hypotheses, we successively increase $d$ until they concur. If they concur when $d=1$, we classify the variable as $I(1)$, or difference stationary. For the anthropogenic variables concurrence occurs when $d=2$. Since the DF-type tests and the KPSS tests reject that these variables are $I(1)$ but do not reject that they are $I(2)$, there is no dilemma here. Matters might have been different if according to the DF-type tests these anthropogenic variables are $I(1)$ but according to KPSS they are $I(2)$.

The required number of augmentations for ADF is moot. The frequently used Schwert criterion uses a standard formula based solely on the number of observations, which is inefficient because it may waste degrees of freedom. As mentioned, we prefer instead to augment the ADF test until its residuals become serially independent according to a lagrange multiplier (LM) test. In most cases 4 augmentations 
Table 1. Stationarity tests for forcings and temperature.

\begin{tabular}{|c|c|c|c|c|c|c|c|c|}
\hline & $\begin{array}{l}\text { Data } \\
\text { period }\end{array}$ & $d$ & Trend & $\mathrm{ADF}$ & DF-GLS & $\begin{array}{r}\text { Phillips- } \\
\text { Perron (PP) }\end{array}$ & KPSS & $\begin{array}{c}\text { Estimate } \\
\text { of } d\end{array}$ \\
\hline $\mathrm{rfCO}_{2}$ & 1850-2007 & $\begin{array}{l}0 \\
0 \\
1 \\
2\end{array}$ & $\begin{array}{l}\text { No } \\
\text { Yes } \\
\text { No } \\
\text { No }\end{array}$ & $\begin{array}{r}2.147 \\
0.716 \\
-0.459 \\
-5.583\end{array}$ & $\begin{array}{r}1.249 \\
-1.438 \\
0.676 \\
-8.548\end{array}$ & $\begin{array}{r}10.589 \\
4.41 \\
-3.253 \\
-20.856\end{array}$ & $\begin{array}{l}3.60 \\
0.809 \\
2.66 \\
0.0349\end{array}$ & 1.61 \\
\hline $\mathrm{rfCH}_{4}$ & $1850-2007$ & $\begin{array}{l}0 \\
0 \\
1 \\
2\end{array}$ & $\begin{array}{l}\text { No } \\
\text { Yes } \\
\text { No } \\
\text { No }\end{array}$ & $\begin{array}{l}-1.990 \\
-3.523 \\
-1.324 \\
-4.932\end{array}$ & $\begin{array}{r}0.689 \\
-3.064 \\
-0.971 \\
-1.701\end{array}$ & $\begin{array}{r}3.341 \\
-1.962 \\
-2.005 \\
-15.517\end{array}$ & $\begin{array}{l}3.84 \\
0.963 \\
1.91 \\
0.107\end{array}$ & 1.14 \\
\hline $\mathrm{rfN}_{2} \mathrm{O}$ & 1850-2007 & $\begin{array}{l}0 \\
0 \\
1 \\
2\end{array}$ & $\begin{array}{l}\text { No } \\
\text { Yes } \\
\text { No } \\
\text { No }\end{array}$ & $\begin{array}{r}1.210 \\
-0.298 \\
0.394 \\
-6.745\end{array}$ & $\begin{array}{r}0.285 \\
-2.338 \\
-1.334 \\
-9.230\end{array}$ & $\begin{array}{r}14.461 \\
5.013 \\
-6.398 \\
-40.369\end{array}$ & $\begin{array}{l}3.56 \\
0.897 \\
3.17 \\
0.0508\end{array}$ & 1.45 \\
\hline $\begin{array}{l}\text { Temperature } \\
\text { (NASA-GISS) }\end{array}$ & 1880-2007 & $\begin{array}{l}0 \\
0 \\
1\end{array}$ & $\begin{array}{l}\text { No } \\
\text { Yes } \\
\text { No }\end{array}$ & $\begin{array}{r}0.135 \\
-2.138 \\
-8.228\end{array}$ & $\begin{array}{r}0.371 \\
-1.481 \\
-11.285\end{array}$ & $\begin{array}{r}-1.821 \\
-5.514 \\
-17.921\end{array}$ & $\begin{array}{l}2.46 \\
0.321 \\
0.139\end{array}$ & 0.94 \\
\hline $\begin{array}{l}\text { Temperature } \\
\text { (BEST) }\end{array}$ & 1850-2007 & $\begin{array}{l}0 \\
0 \\
1\end{array}$ & $\begin{array}{l}\text { No } \\
\text { Yes } \\
\text { No }\end{array}$ & $\begin{array}{r}0.227 \\
-2.393 \\
-8.377\end{array}$ & $\begin{array}{r}0.540 \\
-4.238 \\
-0.713\end{array}$ & $\begin{array}{r}-2.999 \\
-7.077 \\
-23.996\end{array}$ & $\begin{array}{l}3.01 \\
0.397 \\
0.0624\end{array}$ & 1.05 \\
\hline $\begin{array}{l}\text { Solar } \\
\text { irradiance } \\
\text { (NASA-GISS) }\end{array}$ & 1880-2003 & $\begin{array}{l}0 \\
0 \\
1\end{array}$ & $\begin{array}{l}\text { No } \\
\text { Yes } \\
\text { No }\end{array}$ & $\begin{array}{l}-1.258 \\
-4.129 \\
-9.489\end{array}$ & $\begin{array}{r}1.094 \\
-1.016 \\
-0.895\end{array}$ & $\begin{array}{l}-2.034 \\
-4.162 \\
-6.613\end{array}$ & $\begin{array}{l}2.68 \\
0.185 \\
0.0153\end{array}$ & 0.80 \\
\hline $\begin{array}{l}\text { Reflective } \\
\text { tropospheric } \\
\text { aerosols }\end{array}$ & 1880-2003 & $\begin{array}{l}0 \\
0 \\
1 \\
2\end{array}$ & $\begin{array}{l}\text { No } \\
\text { Yes } \\
\text { No } \\
\text { No }\end{array}$ & $\begin{array}{l}-0.796 \\
-2.450 \\
-1.691 \\
-4.724\end{array}$ & $\begin{array}{l}-0.714 \\
-2.121 \\
-1.486 \\
-7.290\end{array}$ & $\begin{array}{r}1.941 \\
-1.458 \\
-1.718 \\
-10.932\end{array}$ & $\begin{array}{l}3.03 \\
0.757 \\
0.991 \\
0.168\end{array}$ & 1.23 \\
\hline $\begin{array}{l}\text { Black } \\
\text { carbon }\end{array}$ & 1880-2003 & $\begin{array}{l}0 \\
0 \\
1 \\
2\end{array}$ & $\begin{array}{l}\text { No } \\
\text { Yes } \\
\text { No } \\
\text { No }\end{array}$ & $\begin{array}{r}0.056 \\
-1.945 \\
-2.795 \\
-4.696\end{array}$ & $\begin{array}{r}0.462 \\
-2.030 \\
-2.440 \\
-7.272\end{array}$ & $\begin{array}{r}1.323 \\
-0.892 \\
-2.731 \\
-11.053\end{array}$ & $\begin{array}{l}2.94 \\
0.692 \\
0.527 \\
0.059\end{array}$ & 1.66 \\
\hline $\begin{array}{l}\text { Stratospheric } \\
\text { aerosols }\end{array}$ & 1880-2003 & 0 & No & -4.743 & -4.183 & -5.330 & 0.212 & 0.10 \\
\hline $\begin{array}{l}\text { Stratospheric } \\
\mathrm{H}_{2} \mathrm{O}\end{array}$ & 1880-2003 & $\begin{array}{l}0 \\
0 \\
1 \\
2\end{array}$ & $\begin{array}{l}\text { No } \\
\text { Yes } \\
\text { No } \\
\text { No }\end{array}$ & $\begin{array}{l}-2.862 \\
-3.896 \\
-3.021 \\
-4.129\end{array}$ & $\begin{array}{l}-2.703 \\
-4.908 \\
-8.446 \\
-8.872\end{array}$ & $\begin{array}{r}3.272 \\
-1.843 \\
-1.954 \\
-16.445\end{array}$ & $\begin{array}{l}3.04 \\
0.762 \\
1.61 \\
0.287\end{array}$ & 1.16 \\
\hline $\begin{array}{l}\text { Ocean heat } \\
\text { content }\end{array}$ & 1952-1996 & $\begin{array}{l}0 \\
0 \\
1\end{array}$ & $\begin{array}{l}\text { No } \\
\text { Yes } \\
\text { No }\end{array}$ & $\begin{array}{l}-1.200 \\
-4.232 \\
-5.621\end{array}$ & $\begin{array}{l}-1.307 \\
-2.746 \\
-2.471\end{array}$ & $\begin{array}{l}-0.824 \\
-2.462 \\
-4.834\end{array}$ & $\begin{array}{l}1.3 \\
0.107 \\
0.13\end{array}$ & \\
\hline
\end{tabular}

Notes: in the ADF, PP and DF-GLS statistics test the null hypothesis is that the $d$-th difference of the variable in the first column is $I$ (1). In the KPSS statistic tests the null hypothesis is that the $d$-th difference is $I(0)$. The final column reports the fractional estimate of $d$ using the method of Geweke and Porter-Hudak (1983).

are needed, however, in the cases of $\mathrm{rfCO}_{2}, \mathrm{rfN}_{2} \mathrm{O}$ and stratospheric $\mathrm{H}_{2} \mathrm{O} 8$ augmentations are needed. In any case, the classification is robust with respect to augmentations in the range of 2-10. Therefore, we do not think that the number of augmentations affects our classifications. The KPSS and Phillips-Perron statistics use the standard nonparametric
Newey-West criteria for calculating robust standard errors. In practice we find that these statistics use about 4 autocorrelations, which is similar to our LM procedure for determining the number of augmentations for ADF.

For each variable we begin in step 1 by testing whether it is stationary ( $d=0$, no deterministic trend). This is easily 
rejected for all the variables in the table below except for stratospheric aerosols. Next, in step 2 we test whether the variables are trend stationary $(d=0$ with a deterministic time trend). According to the KPSS statistic none of the variables is trend stationary. However, in some cases (temperature, solar irradiance) the Phillips-Perron statistic suggests trend stationary as does the ADF statistic for ocean heat.

In step 3 we test for difference stationary ( $d=1$, no deterministic trend). The concurrence criterion is achieved for both measures of temperature (GISS and BEST), solar irradiance and ocean heat content. Therefore, we classify these variables as $I(1)$. Notice that none of these variables is anthropogenic.

In step 4 we test whether these anthropogenic variables are $I(2)$. The test statistics unanimously concur that $d=2$ for $\mathrm{rfCO}_{2}, \mathrm{rfN}_{2} \mathrm{O}$, reflective tropospheric aerosols, black carbon and stratospheric $\mathrm{H}_{2} \mathrm{O}$. The same applies to $\mathrm{rfCH}_{4}$ except for the DF-GLS statistic. Notice that this classification is implied by DF - type tests as well as KPSS. For example, the ADF test statistics reject the hypothesis that $d=1$ but do not reject the hypothesis that $d=2$.

In summary, the time series properties of anthropogenic forcings are fundamentally different to the time series properties of temperature and solar irradiance. Whereas the latter are $I(1)$ variables and are stationary in first differences, the former are $I(2)$ variables and are stationary in second differences. Moreover, this classification is robust and unanimous; all of the anthropogenic forcings are $I(2)$. A joint test of the probability that all anthropogenic forcings are $I(2)$ variables would surely show even more powerfully that anthropogenic forcings are $I(2)$. This unanimity stems from the fact that these forcings are driven by a common anthropogenic factor as we demonstrate below.

We also check whether $\mathrm{rfCO}_{2}$ is $I(1)$ subject to a structural break. A break in the stochastic trend of $\mathrm{rfCO}_{2}$ might create the impression that $d=2$ when in fact $d=1$. We apply the test suggested by Perron and Vogelsang (1992) for the null in which $\mathrm{rfCO}_{2}$ is $I(1)$ with a structural break at some unknown date. The VP statistic (which is the minimal ADF statistic allowing for a break) for the first difference of $\mathrm{rfCO}_{2}$ is -3.877 . Despite the fact that Fig. 2 suggests that this break occurred mid-century, the estimated break point is 1964, but since the critical value of the VP statistic is -4.27 , we can safely reject the hypothesis that $\mathrm{rfCO}_{2}$ is $I(1)$ with a break in its stochastic trend.

\subsection{An anthropogenic trend?}

Normally, $I(1)$ and $I(2)$ variables cannot be cointegrated in which case observed relationships between them are spurious. Since the radiative forcings of greenhouse gases, tropospheric aerosols and black carbon are $I(2)$ they cannot be cointegrated with global temperature and solar irradiance, which are $I(1)$. An exception arises if the $I(2)$ variables happen to be cointegrated between themselves and they cointegrate into an $I(1)$ variable. If this $I(1)$ variable is cointegrated with other $I(1)$ variables, the relationship between the $I(2)$ and $I(1)$ variables is not spurious. In this case the variables are polynomially cointegrated ${ }^{8}$.

We therefore test the hypothesis that the anthropogenic $I$ (2) forcings are cointegrated, and if so, whether they cointegrate into an $I(1)$ variable, which we refer to as the "anthropogenic anomaly". We carry out this test with and without tropospheric aerosols and black carbon (Eqs. 9 and 10 respectively). The least squares estimate of the cointegrating vector for the three greenhouses gases $\left(\mathrm{rCO}_{2}, \mathrm{rfCH}_{4}\right.$ and $\mathrm{rfN}_{2}$ ) using data from $1850-2007$ is

$\mathrm{rfCO}_{2}=10.972+0.046 \mathrm{rfCH}_{4}+10.134 \mathrm{rfN}_{2} \mathrm{O}+g_{1}$

where $g_{1}$ denotes the residual and $\bar{R}^{2}$ of this regression is 0.994 . When tropospheric aerosols and black carbon are included, the OLS estimate using data from 1880 to 2003 is

$$
\begin{aligned}
\mathrm{rfCO}_{2} & =12.554+0.345 \mathrm{rfCH}_{4}+9.137 \mathrm{rfN}_{2} \mathrm{O} \\
& +1.029 \mathrm{BC}+0.441 \text { Reflaer }+g_{2}
\end{aligned}
$$

where $\mathrm{BC}$ denotes radiative forcing of black carbon concentration, Reflaer is the radiative forcing of all reflective aerosols and $g_{2}$ denotes the residual. The $\bar{R}^{2}$ of this regression is 0.996 .

We use a variety of cointegration test statistics to estimate the order of integration of the estimates of $g_{1}$ and $g_{2}$ in Eqs. (9) and (10). Since the ADF and PP statistics for $g_{1}$ and $g_{2}$ exceed their critical values (i.e. they are less negative than $H$ as defined in Table 2), $\hat{g}_{1}$ and $\hat{g}_{2}$ are clearly nonstationary. Matters are quite different in the case of the first differences of these estimates. For $\Delta \hat{g}_{1}$ the ADF and PP statistics are smaller than their critical value, in which case $\hat{g}_{1}$ is $I(1)$. According to the PP statistic so is $\hat{g}_{2} I(1)$, while the ADF statistic falls slightly short of its critical value at $p=0.05$.

Whereas critical values are available for ADF and PP tests for polynomial cointegration, there are no KPSS tests for polynomial cointegration. Such critical values, however, must be smaller than the critical values calculated by Shin (1994) for I(1) variables, just as Haldrup's critical values are more negative than MacKinnon's (1991) for $I$ (1) variables. Therefore, we may use Shin's critical values to bound polynomial cointegration tests using the KPSS methodology. For example, the KPSS statistic for $\hat{g}_{1}$ is 0.75 . Since this clearly exceeds Shin's critical value $(0.21) \hat{g}_{1}$ is not $I(0)$. The KPSS statistic for $\Delta \hat{g}_{1}$ is 0.13 . Since this is less than 0.21 , it might be $I(0)$. A similar pattern is found

\footnotetext{
${ }^{8}$ Enders (2010) refers to this phenomenon by "multicointegration". Granger and Lee $(1989,1990)$ originally defined multicointegration if the difference between the integrals of $I(1)$ variables is $I$ (1). Subsequently, Engsted et al. (1997) interpreted multicointegration in an $I(2)$ context since integrals of $I(1)$ variables are $I(2)$ by definition. Although formally correct, polynomial and multiple cointegration are conceptually different.
} 
Table 2. Cointegration tests for anthropogenic anomalies.

\begin{tabular}{lrrrr}
\hline & $\hat{g}_{1}$ & $\Delta \hat{g}_{1}$ & $\hat{g}_{2}$ & $\Delta \hat{g}_{2}$ \\
\hline ADF & -2.29 & -4.25 & -2.95 & -3.83 \\
PP & -1.53 & -12.78 & -2.37 & -10.57 \\
$H$ & \multicolumn{2}{c}{-3.85} & \multicolumn{2}{c}{-4.1} \\
KPSS & 0.72 & 0.13 & 0.16 & 0.08 \\
Shin & \multicolumn{2}{c}{0.21} & \multicolumn{2}{c}{0.11} \\
\hline
\end{tabular}

Notes: $H$ is the critical value of the polynomial cointegration test statistic ( $p=0.05$ ) according to Haldrup (1994). "Shin" is the critical value $(p=0.05)$ of the cointegration test from Shin (1994).

for $\hat{g}_{2}$ and $\Delta \hat{g}_{2}$. Had the KPSS statistics for $\Delta \hat{g}_{1}$ and $\Delta \hat{g}_{2}$ exceeded 0.21 we would have been able to reject the hypotheses that these anthropogenic forcings are cointegrated.

In summary, both types of cointegration tests in Table 2 suggest that anthropogenic forcings, all of which are $I(2)$ variables "cointegrate down" to an $I(1)$ variable which we refer to as the "anthropogenic anomaly" $(g)$. The existence of this anomaly means that there is an "anthropogenic trend", which is the predicted value of $\mathrm{rfCO}_{2}$ from Eq. (9) in the case of $g_{1}$ and the predicted values of $\mathrm{rfCO}_{2}$ from Eq. (10) in the case of $g_{2}$.

\subsection{Polynomial cointegration test}

We now test whether anthropogenic forcings are polynomially cointegrated with solar irradiance. In Table 3 results are reported using the anthropogenic anomalies estimated in the previous subsection. Model 1 is based on Eq. (9) and uses $g_{1}$ which is estimated from the three greenhouse gases, and model 2 is also based on aerosols and black carbon. Because of data constraints for temperature, aerosols and black carbon the estimation period begins in 1880 .

In model 1 there is a positive effect of solar irradiance on temperature, but the effect of the anthropogenic anomaly is negative. According to AGW this effect should have been positive. In the case of model 1 the critical value of the polynomial cointegration test is $H=-4.56$. The (4th order) ADF statistic is -2.476 and the PP statistic is -4.78 . According to the ADF statistic the null hypothesis of polynomial cointegration is easily rejected, but according to the PP statistic it is not rejected. The KPSS statistic massively rejects the hypothesis that the residuals from model are $I(0)$ since its value greatly exceeds its critical value for $I(1)$ variables. Given the methodological preference for ADF over PP (Sect. 2) and the KPSS statistic, model 1 is not polynomially cointegrated and AGW is rejected.

Similar results are obtained for model 2 except the coefficient on the anthropogenic anomaly is positive instead of negative. According to the ADF and KPSS statistics model 2 is clearly not polynomially cointegrated, but the PP statistic fails to reject at $p=0.05$.
Table 3. Polynomial cointegration tests.

\begin{tabular}{lrr}
\hline Model & 1 & 2 \\
\hline Intercept & 13.80 & 13.79 \\
Solar irradiance & 1.763 & 1.806 \\
Anthropogenic anomaly & -0.0120 & 1.822 \\
ADF & -2.476 & -2.709 \\
PP & -4.78 & -4.96 \\
$H$ & -4.56 & -4.80 \\
KPSS & 0.561 & 0.55 \\
Shin & 0.121 & 0.080 \\
$R^{2}$ adjusted & 0.447 & 0.468 \\
Data period & $1880-2007$ \\
\hline
\end{tabular}

Notes: temperature is regressed on solar irradiance and the anthropogenic anomaly. Model 1 is estimated using the anthropogenic anomaly $\left(g_{1}\right)$ from Eq. (9). Model 2 is estimated using $g_{2}$ from Eq. (10). The first three rows report regression coefficients. The ADF, PP and KPSS statistics refer to the regression residuals. See Table 2 for notes on $H$ and Shin.

\subsection{Reconstructing invalid cointegration tests}

As noted, a number of studies (Kaufmann and Stern, 2002; Kaufmann et al., 2006b, 2010; Mills, 2009) recognise that greenhouse gas forcings are $I(2)$ variables, but their cointegration tests treat the $I(2)$ variables as if they were $I(1)$ variables. To explore the implications of this oversight we use the model specification used in these studies ${ }^{9}$ estimated with data for 1880-2000:

$T=-18.05+1.06 \mathrm{rfCO}_{2}+0.66 S-1.89 \mathrm{rfCH}_{4}+0.71 \mathrm{rfN}_{2} \mathrm{O}$

where $\bar{R}^{2}$ is 0.6829 . According to Eq. (11) temperature varies directly with solar irradiance and $\mathrm{CO}_{2}$ forcing, implying that a doubling of atmospheric $\mathrm{rfCO}_{2}$ raises global temperature by almost 4 degrees. The cointegration test statistics are $\mathrm{ADF}_{4}=-4.76, \mathrm{PP}=-7.73, \mathrm{KPSS}=0.11$. Since the critical values of ADF and PP are -4.18 (MacKinnon, 1991) and the critical value for KPSS is 0.121 (Shin, 1994), it would appear that Eq. (11) is cointegrated. But this result ignores the fact that greenhouse gas forcings are $I(2)$.

The correct cointegration test involves specifying an $I(2)$ variable as a regressand (Haldrup, 1994). Using $\mathrm{rfCO}_{2}$ for such purposes we estimate

$\mathrm{rfCO}_{2}=11.92+0.03 T-0.12 S+0.15 \mathrm{rfCH}_{4}+9.36 \mathrm{rfN}_{2} \mathrm{O}$

where $\bar{R}^{2}=0.996$. According to Eq. (12) temperature is more sensitive to forcings than in Eq. (11), however, despite the high goodness-of-fit, the regression relation is spurious. The critical value of $\mathrm{ADF}$ for polynomial cointegration is -4.56 (Haldrup, 1994) when their test values are -2.22 . The KPSS statistic is 0.277 . Although there is no KPSS-type

\footnotetext{
${ }^{9}$ Since tropospheric aerosols and black carbon did not feature in their model, we do not include these variables. However, this omission does not affect the results.
} 
test statistic for polynomial cointegration, its critical value must be smaller than 0.121, which is its critical value for I(1) variables from Shin (1994). The ADF and KPSS statistics strongly suggest that Eq. (12) is not polynomially cointegrated. Therefore, treating the $I(2)$ variables, which are exclusively anthropogenic, as if they were $I(1)$ variables, predisposes the results into falsely accepting the anthropogenic interpretation of global warming.

In summary, ignoring the fact that greenhouse gas forcings are $I(2)$ and treating them as if they were $I(1)$ variables creates the false impression that global temperature is cointegrated with solar irradiance and greenhouse gas forcings. This spurious relation suggests (spuriously) that a doubling of carbon forcing will raise temperature by about 4 degrees. Once the $I(2)$ status of anthropogenic forcings is taken into consideration, there is no significant effect of anthropogenic forcing on global temperature.

\subsection{Water vapor and ocean heat content}

It has been suggested by Stern (2006) that cointegration tests should take into account the transfer of heat that occurs between the atmosphere and the oceans. The heating of earth by the sun is absorbed mostly by the oceans, and part of this energy is transformed into evaporated water (i.e. latent heat) that heats the atmosphere and cools the ocean. The top ten metres of the water column stores as much heat as the entire atmosphere. There are two issues that are relevant to the statistical tests performed here. First, as discussed in Sect. 2, because water vapor and ocean heat content are entirely dependent on temperature, they cannot affect cointegration tests asymptotically. Therefore, omitting these variables does not affect the tests that we have reported because their effect is intermediated by other variables in the model.

Secondly, because water vapor is dependent on $I(1)$ variables, it is an $I(1)$ variable (see Table 2) as expected. Table 4 reports a cointegration test between water vapor and temperature. The critical value $(p=0.05)$ for the ADF, PP and DF-GLS statistics is -3.426 , which is satisfied by the DF-GLS statistic for the regression residuals, but not by the ADF and PP statistics. On the other hand, the KPSS statistic (0.166) is clearly less than its critical value $(0.314)$, suggesting that the regression residuals are $I(0)$. Therefore, the KPSS statistic suggests that water vapor and temperature are cointegrated, whereas the DF-type tests are ambiguous. Water vapor is $I(1)$ because global temperature is $I(1)$, not the other way around.

The results reported in Table 4 indicate that ocean heat and temperature are not cointegrated. Only one of the cointegration tests (PP) does not reject the null hypothesis. However, this result is obtained from only $45 \mathrm{yr}$ of data, which may be too short for estimating the long-run relationship between ocean heat and surface temperature. Since water vapor and ocean heat are not $I(2)$ variables their omission from models 1 and 2 in Table 3 and Eq. (12) cannot affect our main
Table 4. Water vapor and ocean heat: cointegration tests with temperature.

\begin{tabular}{lrr}
\hline Model & $\begin{array}{r}\text { Water } \\
\text { vapor }\end{array}$ & $\begin{array}{r}\text { Ocean } \\
\text { heat }\end{array}$ \\
\hline Intercept & 13.747 & 14.11 \\
Temperature & 1.763 & 0.018 \\
ADF & -2.805 & -2.370 \\
DF-GLS & -3.587 & -2.84 \\
PP & -1.530 & -3.57 \\
MacKinnon & -3.426 & -3.47 \\
KPSS & 0.166 & 0.44 \\
Shin & 0.314 & 0.314 \\
$R^{2}$ adjusted & 0.658 & 0.260 \\
Data periods & $1880-2007$ & $1952-1996$ \\
\hline
\end{tabular}

Notes: temperature is regressed (OLS) on water vapor and on ocean heat content. The first two rows report the regression coefficients. "MacKinnon" is the critical value of the cointegration test from MacKinnon (1991) and "Shin" is the critical value of the cointegration test statistic in Shin (1994).

result that the anthropogenic $I(2)$ variables are not polynomially cointegrated with temperature and solar irradiance.

\subsection{Nonlinear cointegration}

Thus far our results reject a linear representation of AGW. Suppose instead that AGW is nonlinear. Naturally, a test of this hypothesis requires an explicit nonlinear specification of AGW. Two types of nonlinearity might be involved. First, although anthropogenic forcings are $I(2)$, there might be some nonlinear transformation of them that is $I(1)$. An example of such a nonlinear transformation of a linear $I$ (2) series is economic activity, which is typically $I(2)$ but its logarithm is I (1) (Banerjee et al., 1993, 30-32 pp.). Nonlinear cointegration testing would include nonlinear transformations of the $I$ (2) variables in the cointegrating vector. If these nonlinear transformations turn out to be cointegrated with temperature and solar irradiance, nonlinear AGW would be corroborated. We have experimented with numerous nonlinear transformations ${ }^{10}$ of GHG forcings (n-th roots, reciprocals, logarithms etc), but none of them was found to be $I(1)$.

A second type of nonlinearity might be induced by interactions between variables. However, these interactions would have to be $I(1)$ since temperature is $I(1)$. It would therefore be necessary to interact anthropogenic forcings with some other variable such that their product is $I(1)$. Normally, the product of an $I(1)$ variable and an $I(2)$ variable is not $I(1)$.

\footnotetext{
${ }^{10}$ Choi and Saikkonen (2010) limit their tests to cases in which the covariates are $I(1)$ and their nonlinear transformations are $I(1)$. The nonlinear transformations must be $I(1)$, but there is no reason why the covariates should be $I(1)$. If $x \sim I(0)$ nonlinear cointegration requires that $f(x) \sim I(1)$. If $x \sim I(2)$, it requires $f(x) \sim I(1)$. See Granger and Hallman (1991) on nonlinear transformations of $I$ (1) variables.
} 
We have been unable to find a nonlinear specification of AGW even after extensive data-mining. Based on many experiments, we conclude that anthropogenic forcings are not nonlinearly cointegrated with temperature and solar irradiance. Nor, of course, are they linearly cointegrated.

\subsection{A model of short-run AGW}

The first differences of $I(2)$ variables are necessarily $I(1)$ variables. Although AGW is rejected by polynomial cointegration tests, we investigate a modified version of AGW in which the first differences of anthropogenic forcings are hypothesized to be cointegrated with temperature and solar irradiance. Although there is no physical theory for this modified theory of AGW, we report it out of curiosity and simply because it turns out to be cointegrated. Indeed, it is the only model for which we can find a statistically significant role for anthropogenics.

In this test all the variables are $I(1)$ in which case standard cointegration tests apply. In this modified AGW the null hypothesis is that anthropogenic forcings have a temporary rather than a permanent effect on global temperature. Using data for 1880 to 2007, we find that the statistically significant variables include solar irradiance and the first differences (denoted by $\Delta$ ) in the forcings of three greenhouse gases:

$$
\begin{aligned}
T & =13.821+1.508 S+10.765 \Delta \mathrm{rfCO}_{2} \\
& -46.256 \Delta \mathrm{rfCH}_{4}+36.199 \Delta \mathrm{rfN}_{2} \mathrm{O}
\end{aligned}
$$

where $\bar{R}^{2}$ is 0.6539 . According to Eq. (13) temperature varies with solar irradiance and it varies directly with changes in $\mathrm{rfCO}_{2}$ and $\mathrm{rfN}_{2} \mathrm{O}$ and inversely with the change in $\mathrm{rfCH}_{4}$. This difference between methane and other greenhouse gases has been noted by Liu and Rodriguez (2005) and others. The ADF and PP statistics for the residuals of Eq. (13) are -5.17 and -7.10 , respectively. Since according to MacKinnon (1991) the critical value for cointegration is $-4.85(p=0.05)$ the variables in Eq. (13) are cointegrated. Note that since the variables in Eq. (13) are $I(1)$ we do not use critical values for polynomial cointegration. The KPSS statistic for the residuals of Eq. (13) is 0.303 , which exceeds its critical value (0.121) in Shin (1994). Therefore, even Eq. (13) is not unambiguously cointegrated.

\subsection{Error correction}

Cointegration implies error correction, which is the dynamic process through which temperature converges to its longterm equilibrium level (Engle and Granger, 1987). We report the error correction model (ECM) for global temperature since this is the main variable of interest here. This model uses the residuals $(u)$ from Eq. (13), which measure the deviation of temperature from its long-term equilibrium level. Its dynamic specification is estimated using the general-to-specific methodology, which nests-down to a restricted dynamic specification (see e.g. Hendry, 1995 for details of this methodology) which in the present case yields:

$$
\begin{gathered}
\Delta T_{t}=0.005-0.14 \Delta T_{t-2}-0.20 \Delta T_{t-3}+0.71 \Delta_{2}^{2} S_{t} \\
(0.05) \quad(1.71) \quad(2.51)
\end{gathered}
$$

Since the variables in Eq. (14) are stationary and their coefficient estimates have standard distributions, we report absolute $t$-statistics in parentheses. Since the critical value for the $t$-statistic $(p=0.05)$ is 1.98 , all the parameter estimates in Eq. (14) are statistically significant with the possible exception of the first. In Eq. (14) the change in temperature varies directly with the $3 \mathrm{rd}$ difference in $\mathrm{rfCO}_{2}$ and the twice lagged 2 nd difference in $\mathrm{rfN}_{2} \mathrm{O}$. It also varies directly with the 2 nd ("seasonal") difference of solar irradiance $\left(\Delta_{2}^{2} S_{t}=\Delta S_{t}-\Delta S_{t-2}\right)$. It does not depend at all on methane. There is evidence of 2 nd and 3 rd order negative autoregression in the change in temperature. Finally, the error correction coefficient is very significant and is equal to a half. This means that when the temperature deviates from its steady state equilibrium as determined in Eq. (14) about half of the deviation is corrected within a year. These estimated speeds of adjustment are similar to those obtained from time series models (Liu and Rodriguez, 2005; Kaufmann et al., 2006a). The Durbin Watson (DW) and Lagrange Multiplier (LM) statistics for serial correlation in the residuals indicate that the dynamic specification of Eq. (14) is appropriate. The $t$-statistic on the error correction term is large and negative $(-6.38)$. This constitutes further evidence that Eq. (14) is cointegrated. Finally, the standard error of estimate (se) means that the standard deviation of the predicted value of temperature is $0.12^{\circ} \mathrm{C}$ which is large relative to the change in temperature that occurred during 1880-2007.

\subsection{Robustness checks}

We carry out a variety of robustness checks regarding the rejection of AGW by polynomial cointegration tests reported in Table 3, and the non-rejection of modified AGW (Eq. 13). These checks are additional to those that we have already reported, such as nonlinear cointegration tests. The robustness checks fall into three distinct groups. First, we check for the presence of finite sample bias. Second, we check whether our results are robust with respect to different estimation methods. Finally, we check whether they are robust with respect to different data measurements.

We use the 3 -stage procedure ${ }^{11}$ suggested by Engle and Yoo (1991) to test for finite sample bias in the estimates of

\footnotetext{
${ }^{11}$ The residuals of Eq. (13) are regressed on the covariates in Eq. (13) multiplied by the error correction coefficient from Eq. (14), which is -0.5 . If these residuals are $I(0) R^{2}$ should be zero since the covariates are $I(1)$. The adjusted $R^{2}$ is 0.0033 and the largest $t$-statistic is 1.4 .
} 
equation (13). Since the $p$-value of the $F$-statistic for the 3rd stage (for which Eq. 13 is the 1st stage and Eq. 14 is the 2 nd stage) is 0.36 , we may reject the hypothesis of finite sample bias in Eq. (13). We can only apply this test to cointegrated results. We therefore cannot apply it to models 1 and 2 in Table 3 since they are not polynomially cointegrated. Nevertheless, the fact that finite sample bias cannot be detected in Eq. (13) suggests that finite sample bias does not explain why AGW is not polynomially cointegrated. If there is no finite sample bias in Eq. (13) where the parameter estimates are $T^{3 / 2}$-consistent, there is all the more reason to believe that finite sample bias is not present in our polynomial cointegration tests where the estimates are $T^{5 / 2}$-consistent. Therefore, our failure to corroborate AGW according to which temperature and solar irradiance are polynomially cointegrated with anthropogenic forcings is not attributable to lack of data and associated finite sample bias.

Next, we use DOLS (Stock and Watson, 1993) rather than OLS to estimate models 1 and 2 in Table 3 and Eq. (13). Since DOLS requires the specification of leads and lags in the first differences of the covariates, we use two leads and lags. The DOLS estimates of the coefficients are 2.1 (solar irradiance) and $0.75(\mathrm{~g})$ for model 1 and 2.04 and 2.09 for model 2. These estimates are larger than their OLS counterparts in Table 2. The ADF polynomial cointegration test statistics are -2.96 and -3.11 , respectively, which although smaller than their counterparts in Table 3 still exceed their critical values of -4.56 and -4.8 . Therefore, the DOLS estimates confirm the previous conclusion that AGW is a spurious regression phenomenon.

The ADF statistic for the DOLS estimate of Eq. (13) is -4.83 which is almost identical to its critical value $(-4.85$ at $p=0.05)$. Since the $\mathrm{p}$-value of the DOLS cointegration test exceeds its OLS counterpart we are less sure that Eq. (13) is cointegrated. However, since the $t$-statistic of the error correction coefficient in Eq. (14) (-6.48) is much smaller than its critical value (Ericsson and MacKinnon, 2002) the ECM cointegration test serves as an independent robustness check. Since the OLS and EC cointegration tests corroborate modified AGW and the DOLS test is borderline we are inclined to conclude that there is a temporary effect of anthropogenic forcings on temperature.

We have estimated Eq. (13) using revised and extended (to 2006) data for solar irradiance (Lean and Rind, 2009). Prior to 1980 these data were based on various proxy measures. Data since 1980 are based on instrumental measurements taken from satellites. Whereas the data in NASA GISS used $15 \mathrm{yr}$ of satellite data, the revised data use $26 \mathrm{yr}$ of satellite data. We note that the revised data behave quite differently from the original in that the ratio between the revised data and the original decreases during 1850 to 1950 but increases subsequently. Also the fractional estimate of $\mathrm{d}$ for the revised data is only 0.16 instead of 0.8 in Table 1 , suggesting that solar irradiance is stationary. We have focused on the original data since these were used by others who claimed that global temperature is cointegrated with solar irradiance and greenhouse gas forcings.

When we use these revised data models 1 and 2 in Table 3 are still polynomially uncointegrated. However, Eq. (13) ceases to be cointegrated. This happens because, as noted, the revised data are quite different to the original. Therefore these revised data reject both AGW and its modified version. Finally, we re-estimated all the models using temperature as measured by the Berkeley Earth Surface Temperature Study (BEST) instead of NASA-GISS. Data for BEST are available from 1850 rather than 1880 , which adds $30 \mathrm{yr}$ more data for our cointegration tests. However, BEST unlike NASA-GISS refers to land temperature only. BEST, like temperature in NASA-GISS, is difference stationary. Estimates of models 1 and 2 and Eq. (13) using BEST are almost identical to their NASA-GISS counterparts. AGW continues to be polynomially uncointegrated, while modified AGW continues to be cointegrated.

Our results are therefore robust with respect to a variety of misspecification tests and alternative estimators and data. Temperature is not polynomially cointegrated with solar irradiance and anthropogenic forcing, but it appears to be cointegrated with solar irradiance and changes in anthropogenic forcings.

\section{Discussion}

We have shown that anthropogenic forcings do not polynomially cointegrate with global temperature and solar irradiance. Therefore, data for 1880-2007 do not support the anthropogenic interpretation of global warming during this period. This key result is shown graphically in Fig. 3 where the vertical axis measures the component of global temperature that is unexplained by solar irradiance according to our estimates. In panel a the horizontal axis measures the anomaly in the anthropogenic trend when the latter is derived from forcings of carbon dioxide, methane and nitrous oxide. In panel $b$ the horizontal axis measures this anthropogenic anomaly when apart from these greenhouse gas forcings, it includes tropospheric aerosols and black carbon. Panels a and $b$ both show that there is no relationship between temperature and the anthropogenic anomaly, once the warming effect of solar irradiance is taken into consideration.

However, we find that greenhouse gas forcings might have a temporary effect on global temperature. This result is illustrated in panel c of Fig. 3 in which the horizontal axis measures the change in the estimated anthropogenic trend. Panel c clearly shows that there is a positive relationship between temperature and the change in the anthropogenic anomaly once the warming effect of solar irradiance is taken into consideration.

Currently, most of the evidence supporting AGW theory is obtained by calibration methods and the simulation of GCMs. Calibration shows, e.g. Crowley (2000), that to 
a.

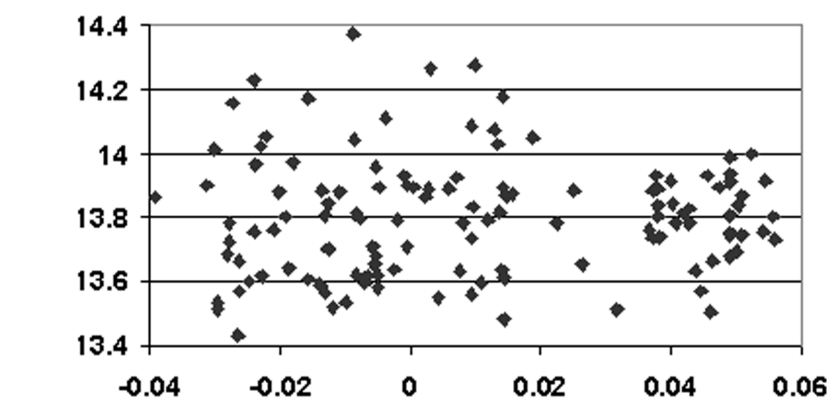

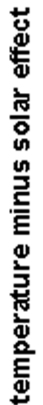

b.

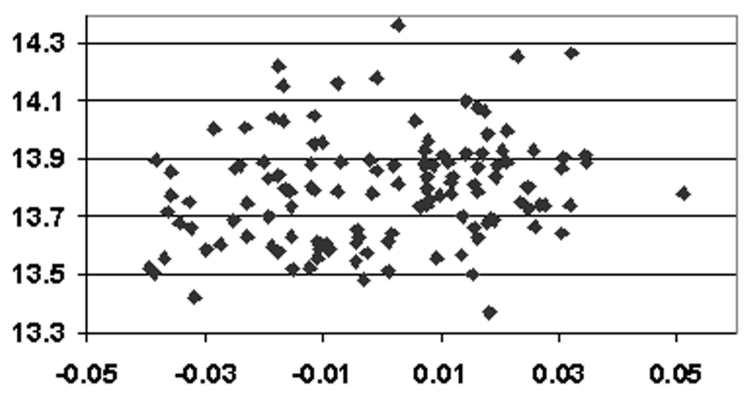

c.

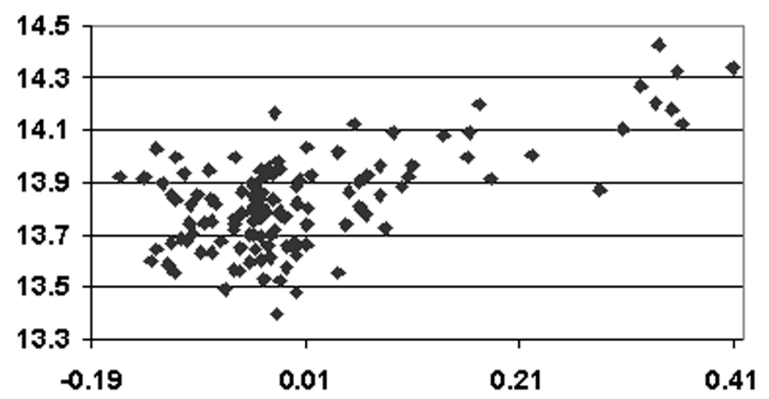

anthropogenic trend anomaly

Fig. 3. Statistical association between (scatter plot of) anthropogenic anomaly (abscissa), and net temperature effect (i.e. temperature minus the estimated solar irradiance effect; ordinates). Panels (a)-(c) display the results of the models presented in models 1 and 2 in Table 3 and Eq. (13), respectively. The anthropogenic trend anomaly sums the weighted radiative forcings of the greenhouse gases $\left(\mathrm{CO}_{2}, \mathrm{CH}_{4}\right.$ and $\left.\mathrm{N}_{2} \mathrm{O}\right)$. The calculation of the net temperature effect (as defined above) change is calculated by subtracting from the observed temperature in a specific year the product of the solar irradiance in that year times the coefficient obtained from the regression of the particular model equation: 1.763 in the case of model 1 (a); 1.806 in the case of model 2 (b); and 1.508 in the case of Eq. (13) (c).

explain the increase in temperature in the 20th century, and especially since 1970 , it is necessary to specify a sufficiently strong anthropogenic effect. However, calibrators do not report tests for the statistical significance of this effect, nor do they check whether the effect is spurious ${ }^{12}$. The implication of our results is that the permanent effect is not statistically significant. Nevertheless, there seems to be a temporary anthropogenic effect. If the effect is temporary rather than permanent, a doubling, say, of carbon emissions would have no long-run effect on Earth's temperature, but it would increase it temporarily for some decades. Indeed, the increase in temperature during 1975-1995 and its subsequent stability are in our view related in this way to the acceleration in carbon emissions during the second half of the 20th century (Fig. 2). The policy implications of this result are major since an effect which is temporary is less serious than one that is permanent.

The fact that since the mid 19th century Earth's temperature is unrelated to anthropogenic forcings does not contravene the laws of thermodynamics, greenhouse theory, or any other physical theory. Given the complexity of Earth's climate, and our incomplete understanding of it, it is difficult to attribute to carbon emissions and other anthropogenic phenomena the main cause for global warming in the 20th century. This is not an argument about physics, but an argument about data interpretation. Do climate developments during the relatively recent past justify the interpretation that global warming was induced by anthropogenics during this period? Had Earth's temperature not increased in the 20th century despite the increase in anthropogenic forcings (as was the case during the second half of the 19th century), this would not have constituted evidence against greenhouse theory. However, our results challenge the data interpretation that since 1880 global warming was caused by anthropogenic phenomena.

Nor does the fact that during this period anthropogenic forcings are $I(2)$, i.e. stationary in second differences, whereas Earth's temperature and solar irradiance are $I(1)$, i.e. stationary in first differences, contravene any physical theory. For physical reasons it might be expected that over the millennia these variables should share the same order of integration; they should all be $I(1)$ or all $I(2)$, otherwise there would be persistent energy imbalance. However, during the last $150 \mathrm{yr}$ there is no physical reason why these variables should share the same order of integration. However, the fact that they do not share the same order of integration over this period means that scientists who make strong interpretations about the anthropogenic causes of recent global warming should be cautious. Our polynomial cointegration tests challenge their interpretation of the data.

Finally, all statistical tests are probabilistic and depend on the specification of the model. Type 1 error refers to the probability of rejecting a hypothesis when it is true (false

\footnotetext{
${ }^{12} \mathrm{GCMs}$ embody hundreds if not thousands of unknown parameters to be calibrated. In practice this leaves few if any degrees of freedom to carry out meaningful statistical tests. This explains why observationally similar GCMs often generate quite different forecasts.
} 
Data Appendix.

\begin{tabular}{|c|c|c|c|}
\hline Variable name & Unit & Data source & Link \\
\hline Temperature & ${ }^{\circ} \mathrm{C}$ anomaly & $\begin{array}{l}\text { NASA-GISS surface } \\
\text { temperature analysis }\end{array}$ & http://data.giss.nasa.gov/gistemp/ \\
\hline $\begin{array}{l}\text { Temperature (Mann, } \\
2008 \text { reconstruction) }\end{array}$ & ${ }^{\circ} \mathrm{C}$ anomaly & Mann et al. (2008) & \\
\hline $\begin{array}{l}\text { Temperature } \\
\text { (Berkeley earth } \\
\text { surface } \\
\text { temperature) }\end{array}$ & ${ }^{\circ} \mathrm{C}$ anomaly & $\begin{array}{l}\text { Berkeley earth } \\
\text { surface temperature } \\
\text { study }\end{array}$ & http://berkeleyearth.org/analysis.php \\
\hline Solar irradiance & $\mathrm{W} \mathrm{m}^{-2}$ & Lean et al. (1995) & \\
\hline $\begin{array}{l}\text { Solar irradiance - } \\
\text { updated }\end{array}$ & $\mathrm{W} \mathrm{m}^{-2}$ & $\begin{array}{l}\text { Lean and Rind } \\
\text { (2009) }\end{array}$ & \\
\hline $\mathrm{CO}_{2}$ concentrations & ppm & NASA-GISS & http://data.giss.nasa.gov \\
\hline $\mathrm{N}_{2} \mathrm{O}$ concentrations & ppm & NASA-GISS & http://data.giss.nasa.gov \\
\hline $\mathrm{CH}_{4}$ concentrations & ppm & NASA-GISS & http://data.giss.nasa.gov \\
\hline Ocean heat content & $10^{22}$ joules & Levitus et al. (2005) & \\
\hline $\begin{array}{l}\text { Black carbon } \\
\text { (forcing) }\end{array}$ & $\mathrm{W} \mathrm{m}^{-2}$ & NASA-GISS & http://data.giss.nasa.gov/modelforce/RadF.txt \\
\hline $\begin{array}{l}\text { Reflective } \\
\text { tropospheric } \\
\text { aerosols (forcing) }\end{array}$ & $\mathrm{W} \mathrm{m}^{2}$ & NASA-GISS & http://data.giss.nasa.gov/modelforce/RadF.txt \\
\hline $\begin{array}{l}\text { Stratospheric } \\
\text { aerosols (forcing) }\end{array}$ & $\mathrm{W} \mathrm{m}^{-2}$ & NASA-GISS & http://data.giss.nasa.gov/modelforce/RadF.txt \\
\hline $\begin{array}{l}\text { Water vapour } \\
\text { (forcing) }\end{array}$ & $\mathrm{W} \mathrm{m}^{2}$ & NASA-GISS & http://data.giss.nasa.gov/modelforce/RadF.txt \\
\hline
\end{tabular}

Notes: concentrations of $\mathrm{CO}_{2}, \mathrm{~N}_{2} \mathrm{O}$ and $\mathrm{CH}_{4}$ are converted into radiative forcings using the formula provided by Myhre et al. (1998).

positive) and type 2 error refers to the probability of not rejecting a hypothesis when it is false (false negative). In our case the type 1 error is very small because anthropogenic forcing is $I(1)$ with very low probability, and temperature is polynomially cointegrated with very low probability. Also we have experimented with a variety of model specifications and estimation methodologies. This means, however, that as with all hypotheses, our rejection of AGW is not absolute; it might be a false positive, and we cannot rule out the possibility that recent global warming has an anthropogenic footprint. However, this possibility is very small, and is not statistically significant at conventional levels.

Edited by: N. de Noblet

\section{References}

Banerjee, A., Dolado, J. J., Galbraith, J. W., and Hendry, D. F.: Cointegration, Error Correction, and the Econometric Analysis of Non-stationary Data, Oxford University Press, 1993.

Choi, I. and Saikkonen, P.: Tests for nonlinear cointegration, Econom. Theory, 26, 682-709, 2010.
Crowley, T. J.: Causes of climate change over the past 1000 years, Science, 289, 270-277, 2000.

Davidson, R. and MacKinnon, J. G.: Econometric Theory and Methods, Oxford University Press, 2009.

Dickey, D. A. and Fuller, W. A.: Likelihood ratio statistics for autoregressive time-series with a unit root, Econometrica, 49, 1057-1072, 1981.

Elliott, G., Rothenberg, T. J., and Stock, J. H.: Efficient tests for an autoregressive unit root, Econometrica, 64, 813-836, 1996.

Enders, W.: ARIMA and cointegration tests of PPP under fixed and flexible exchange rate regimes, Rev. Econom. Stat., 70, 504-508, 1988.

Enders, W.: Applied Econometric Time Series, 3rd Edn., John Wiley, 2010.

Engle, R. F. and Granger, C. W. J.: Co-integration and error correction: representation, estimation and testing, Econometrica, 55, 251-276, 1987.

Engle, R. F. and Yoo, B. S.: Cointegrated economic time series: an overview with new results, in: Long Run Economic Relationships: Readings in Cointegration, edited by: Engle, R. F. and Granger, C. W. J., Oxford University Press, chapter 12, 1991.

Engsted, T., Gonzalo, J., and Haldrup, N.: Testing for multicointegration, Econom. Lett., 56, 259-266, 1997.

Ericsson, N. R. and MacKinnon, J. G.: Distributions of error correction tests for cointegration, Economet. J., 5, 285-318, 2002. 
Geweke, J. and Porter-Hudak, S.: The estimation and application of long memory time series models, J. Time Ser. Anal., 4, 221-238, 1983.

Granger, C. W. J. and Hallman, J. J.: Nonlinear transformations of integrated time series, J. Time Ser. Anal., 12, 207-224, 1991.

Granger, C. W. J. and Joyeaux, R.: An introduction to long-memory models and fractional differencing, J. Time Ser. Anal., 1, 15-39, 1981.

Granger, C. W. J. and Lee, T.-W.: Investigation of production and sales and inventory relationships using multicointegration and non-systematic error correction models, J. Appl. Economet., 4, 145-189, 1989.

Granger, C. W. J. and Lee, T.-W.: Multicointegration, Adv. Economet., 8, 77-84, 1990.

Greene, W. A.: Econometric Analysis, 7th Edn., Harlow, Pearson, 2012

Haldrup, N.: The asymptotics of single-equation cointegration regressions with $I(0)$ and $I(0)$ variables, J. Economet., 63, 151181, 1994.

Hansen, J., Ruedy, R., Glascoe, J., and Sato, M.: GISS analysis of surface temperature change, J. Geophys. Res., 104, 30997 31022, doi:10.1029/1999JD900835, 1999.

Hansen, J. E., Ruedy, R., Sato, M., Imhoff, M., Lawrence, W., Easterling, D., Peterson, T., and Karl, T.: A closer look at United States and global surface temperature change, J. Geophys. Res., 106, 23947-23963, doi:10.1029/2001JD000354, 2001.

Hendry, D. F.: Dynamic Econometrics, Oxford University Press, 1995.

Hendry, D. F. and Ericsson, N. R.: An econometric analysis of UK money demand in monetary trends in the United States and United Kingdom by Milton Friedman and Anna J. Schwartz, Am. Econ. Rev., 81, 8-38, 1991.

IPCC - Intergovernmental Panel on Climate Change: IPCC Fourth Assessment Report: Climate Change, 2007.

Johansen, S.: Statistical analysis of cointegration vectors, J. Econom. Dynam. Control, 12, 231-254, 1988.

Johansen, S.: Likelihood-based Inference in Cointegrated Vector Autoregressive Models, Oxford University Press, 1995.

Johansen, S. and Juselius, K.: Identification of the Long-Run and the Short-Run Structure: an Application to the IS-LM Model, J. Economet., 63, 7-36, 1998.

Juselius, K.: The Cointegrated VAR Model, Oxford University Press, 2007.

Kaufmann, A. and Stern, D. I.: Evidence for human influence on climate from hemispheric temperature relations, Nature, 388, 3944, 1997.

Kaufmann, A. and Stern, D. I.: Cointegration analysis of hemispheric temperature relations, J. Geophys. Res., 107, ACL8.18.10, 2002.

Kaufmann, A., Kauppi, H., and Stock, J. H.: Emissions, concentrations and temperature: a time series analysis, Climatic Change, 77, 248-278, 2006a.

Kaufmann, A., Kauppi, H., and Stock J. H.: The relationship between radiative forcing and temperature: what do statistical analyses of the instrumental temperature record measure?, Climatic Change, 77, 279-289, 2006b.

Kaufmann, A., Kauppi, H., and Stock, J. H.: Does temperature contain a stochastic trend?, Climatic Change, 101, 395-405, 2010.
Kwiatkowski, D., Phillips, P. C. B., Schmidt, P., and Shin, Y.: Testing the null hypothesis of stationarity against the alternative of a unit root, J. Economet., 54, 159-178, 1992.

Lean, J. and Rind, D.: How will earth's surface temperature change in future decades, Geophys. Res. Lett., 36, 1-5, 2009.

Lean, J., Beer, J., and Bradley, R.: Reconstruction of solar irradiance since 1610: Implications for climate change, Geophys. Res. Lett., 22, 3195-3198, 1995.

Lee, J. and Strazicich, M.: Testing the null of stationarity in the presence of a structural break, Appl. Econom. Lett., 8, 377-382, 2001.

Levitus, S., Antonov, J., and Boyer, T.: Warming of the world ocean 1955-2003, Geophys. Res. Lett., 32, L02604, doi:10.1029/2004GL021592, 2005.

Liu, H. and Rodriguez, G.: Human activities and global warming: a cointegration analysis, Environ. Model. Softw., 20, 761-773, 2005.

MacKinnon, J.: Critical values for cointegration tests, in: Long-run Economic Relations, Readings in Cointegration, edited by: Engle, R. F. and Granger, C. W. J., Oxford University Press, Oxford, 267-276, 1991.

Maddala, G. S.: Introduction to Econometrics, 3rd Edn., J. Wiley, New York, 2001.

Maddala, G. S. and Kim, I. M.: Unit Roots, Cointegration and Structural Change, Cambridge University Press, 1998.

Mann, M. E., Zhang, Z. Hughes, M. K., Bradley, R. S., Miller, S. K., Rutherford, S., and Ni, F.: Proxy-based reconstructions of hemispheric and global surface temperature variations over the past two millennia, P. Natl. Acad. Sci., 105, 13252-13257, 2008.

Mills, T. C.: Time series modelling of two millenia of northern hemisphere temperatures: long memory or level shifts, J. Roy. Stat. Soc. A, 170, 83-94, 2007.

Mills, T. C.: How robust is the long-run relationship between temperature and radiative forcing?, Climatic Change, 94, 351-361, 2009.

Myhre, G., Highwood, E. J., Shine, K. P., and Stordal, F.: New estimates of radiative forcing due to well mixed greenhouse gases, Geophys. Res. Lett., 25, 2715-2718, 1998.

North, G. R, Cahalan, R. E., and Coakley Jr., J. A.: Energy balance climate models, Rev. Geophys. Space Phys., 19, 91-121, 1981.

Perron, P. and Vogelsang, T. J.: Testing for a unit root in a time series with a changing mean: corrections and extensions, J. Business Econ. Stat., 10, 467-470, 1992.

Phillips, P. C. B.: Understanding spurious regressions in econometrics, J. Economet., 33, 311-340, 1986.

Phillips, P. C. B. and Perron, P.: Testing for a unit root in time series regression, Biometrika, 75, 335-346, 1988.

Said, S. and Dickey, D.: Testing for unit roots in autoregressive moving average model with unknown order, Biometrika, 71, 599-607, 1984.

Shin, Y.: A residual-based test of the null of cointegration against the alternative of no cointegration, Economet. Theory, 10, 91115, 1994.

Stern, D. I.: An atmosphere - ocean time series model of global climate change, Comput. Stat. Data Anal., 51, 1330-1346, 2006.

Stern, D. I. and Kaufmann, R. K.: Econometric analysis of global climate change, Environ. Model. Softw., 14, 597-605, 1999. 
Stern, D. I. and Kaufmann, R. K: Detecting a global warming signal in hemispheric temperature series: a structural time series analysis, Climatic Change, 47, 411-438, 2000.

Stock, J. H. and Watson, M. W.: A simple estimator of cointegrating vectors in higher order integrated systems, Econometrica, 61, 783-820, 1993
Yule, U.: On the theory of correlation, J. Roy. Stat. Soc. A, 89, 1-69, 1897. 